\title{
KAJIAN RISIKO BENCANA KEGAGALAN TEKNOLOGI PADA JEMBATAN KERETA API
}

\section{RISK ASSESSMENT ON SEISMIC VULNERABILITY OF RAILWAY BRIDGES}

\author{
Mulyo Harris Pradono \\ Pusat Teknologi Reduksi Risiko Bencana \\ Badan Pengkajian dan Penerapan Teknologi \\ Gedung 820, GEOSTECH, PUSPIPTEK, Kota Tangerang Selatan \\ e-mail:mulyo.harris@bppt.go.id
}

\begin{abstract}
Disaster from technological failure is a type of disaster event caused by design errors, operations errors, negligence, and human intentional use of technology. One example of technological failure is transportation accidents. One source of accidents that may cause a lot of casualties is a train accident caused by the failure of the bridge passed by the train. To reduce the risk of catastrophic failure of railway bridges, we developed a method of measuring the dimensions and analysis of railway bridge deflection. With this method, it can be shown that that some of the studied bridges have calculated deflections value that exceed the permitted deflection requirements in the regulation. Those bridges need more thorough assessment in order to repair or replace the bridges.
\end{abstract}

Keywords: Rapid Assessment, Earthquakes, Highrise Buildings, Vulnerability

\begin{abstract}
ABSTRAK
Bencana gagal teknologi merupakan jenis kejadian bencana yang diakibatkan oleh kesalahan desain, pengoperasian, kelalaian, dan kesengajaan manusia dalam penggunaan teknologi. Salah satu contoh kegagalan teknologi adalah kecelakaan transportasi. Salah satu sumber kecelakaan yang dapat menimbulkan korban banyak adalah kecelakaan kereta api yang diakibatkan oleh gagalnya jembatan yang dilewati oleh kereta tersebut. Untuk mengurangi risiko bencana kegagalan jembatan kereta api, maka dikembangkan metoda pengukuran dimensi dan analisis lendutan jembatan kereta api. Dengan metode ini, dapat ditunjukkan bahwa beberapa jembatan yang dikaji mempunyai nilai lendutan hitung yang melampaui persyaratan lendutan ijin di peraturan. Jembatan-jembatan tersebut harus mendapatkan kajian lebih lanjut sehingga dapat dilakukan langkah perbaikan atau penggantian jembatan.
\end{abstract}

Katakunci: Bencana Gagal Teknologi, Jembatan, Kereta Api, Lendutan

\section{PENDAHULUAN}

Undang-undang No. 24 Tahun 2007 (Presiden Republik Indonesia, 2007) tentang Penanggulangan Bencana menyebutkan bahwa potensi penyebab bencana di Indonesia dapat dikelompokkan dalam tiga jenis bencana, yaitu bencana alam, bencana non alam, dan bencana sosial. Bencana alam antara lain berupa gempa bumi karena alam, letusan gunung berapi, angin topan, banjir, tanah longsor, kekeringan, kebakaran hutan/lahan karena faktor alam, hama penyakit tanaman, epidemi, wabah, kejadian luar biasa, dan kejadian antariksa/benda-benda angkasa. Bencana non alam antara lain kebakaran hutan/lahan yang disebabkan oleh manusia, kecelakan transportasi, kegagalan konstruksi/teknologi, dampak industri, ledakan nuklir, pencemaran lingkungan dan kegiatan keantariksaan. Bencana sosial antara lain berupa kerusuhan sosial dan konflik sosial dalam masyarakat.

Bencana gagal teknologi merupakan jenis kejadian bencana yang diakibatkan oleh kesalahan desain, pengoperasian, kelalaian, dan kesengajaan manusia dalam penggunaan teknologi. Salah satu contoh kegagalan teknologi adalah kecelakaan transportasi. Salah satu sumber kecelakaan yang dapat menimbulkan korban banyak adalah kecelakaan kereta api yang diakibatkan oleh gagalnya jembatan yang dilewati oleh kereta tersebut. Untuk mengurangi risiko bencana kegagalan jembatan kereta api, maka 
dikembangkan metoda pengukuran dimensi dan analisis lendutan jembatan kereta api.

Metode yang digunakan didasarkan pada Pemeriksaan Jembatan Rangka Baja (Pedoman Konstruksi Bangunan. 2009), dengan menambah kajian pada pemodelan struktur:

a. mengukur dimensi semua bagian struktural dari jembatan yang mempengaruhi lendutan struktur

b. menentukan jenis material baja yang digunakan

c. menentukan jenis pembebanan didasarkan pada peraturan yang berlaku

d. melakukan pemodelan struktur jembatan secara numerik dan memberikan simulasi beban untuk menghitung kekuatan dan menghitung lendutan yang terjadi

e. menentukan apakah lendutan yang terjadi memenuhi syarat atau tidak

\section{METODE PENELITIAN}

\subsection{Waktu dan Tempat Penelitian}

Penelitian dan pengkajian risiko bencana kegagalan teknologi jembatan kereta api ini dilakukan pada jangka waktu mulai tanggal 30 Oktober 2017 sampai dengan 08 November 2017, berlokasi pada beberapa percontoh jembatan di jalur utara rel kereta api di Jawa Barat.

\subsection{Bahan dan Data}

Ada lima buah jembatan yang dilakukan pengkajian. Karena dalam tulisan ini yang ingin disampaikan adalah metodenya dan bukan hasilnya, maka nama-nama jembatan diganti menjadi nama umum saja:

a. Jembatan KA 1, jalur KA utara di Jawa Barat

b. Jembatan KA 2, jalur KA utara di Jawa Barat

c. Jembatan KA 3, jalur KA utara di Jawa Barat

d. Jembatan KA 4, jalur KA utara di Jawa Barat

e. Jembatan KA 5, jalur KA utara di Jawa Barat

Untuk memperoleh data, dilakukan beberapa kegiatan sebagai berikut:

a. Pengamatan visual terhadap kondisi jembatan (karat, dan sebagainya)

b. Penentuan jenis jembatan baja (rangka baja, plate girder, atau baja profil, dan sebagainya)

c. Penentuan jenis baja yang digunakan

d. Panjang bentang jembatan

e. Dimensi flange, web, panjang rangka, balok melintang, dan jarak bantalan rel.

\subsection{Analisis Data}

adalah:

Analisis yang dilakukan terhadap data

a. Data dimensi struktur jembatan dimasukkan dalam program analisis struktur untuk dibuat model numerik dari jembatan

b. Beban rencana yang sesuai dengan peraturan yang berlaku (PM 60 tahun 2012) dimasukkan dalam program

c. Lendutan struktur yang terrjadi akibat beban tersebut dibandingkan dengan persyaratan lendutan di dalam peraturan yang berlaku (PM 60 tahun 2012)

\section{HASIL DAN}

\section{PEMBAHASAN 3.1. Hasil}

\subsubsection{Jembatan KA 1}

Jembatan KA 1 masih dirancang dengan beban maksimum 75\% dari RM 21 (beban dalam peraturan PM. 60 Tahun 2012). Jembatan tersebut dibangun pada masa penjajahan Belanda dan merupakan jembatan rangka baja dengan bentang $25 \mathrm{~m}$ dan.

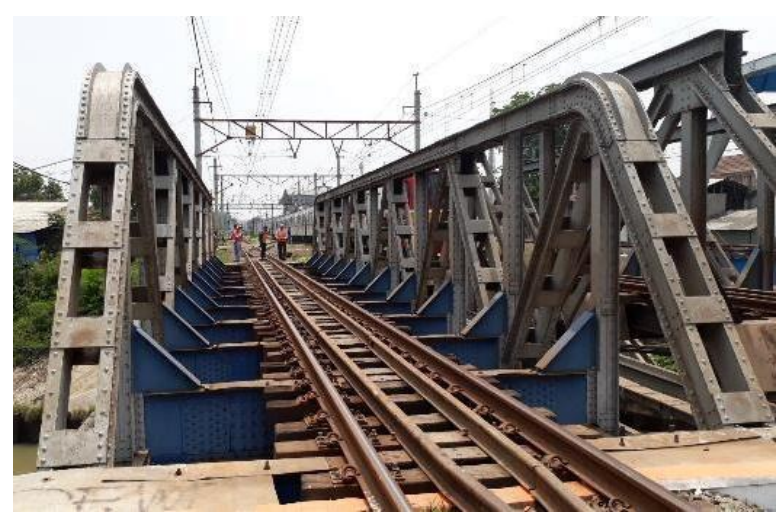

Gambar 1. Jembatan KA 1, Rangka Baja Menggunakan Plate Girder Profile dengan Bentang $25 \mathrm{~m}$

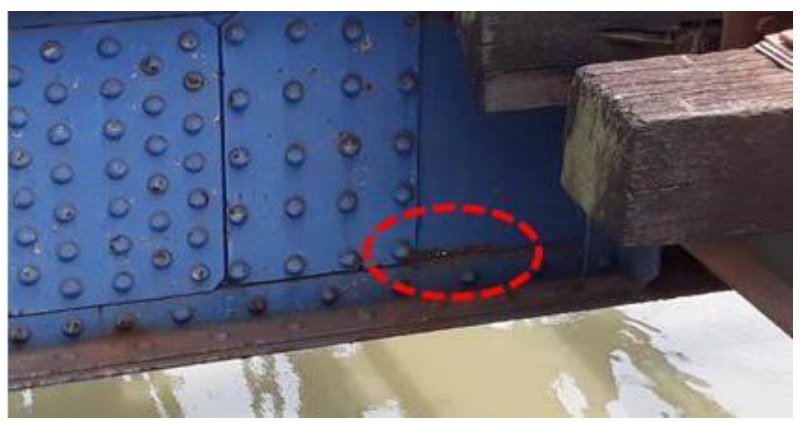

Gambar 2. Korosi yang Telah Terjadi pada Web Plate pada Plate Girder Balok Melintang pada Jembatan KA 1 


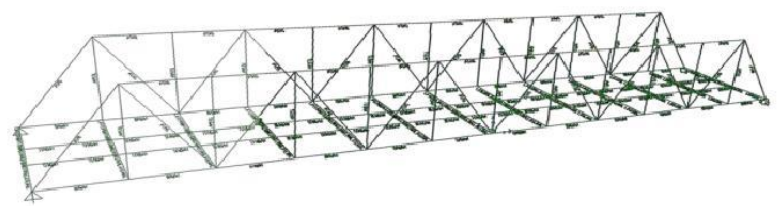

Gambar 3. Model Numerik Jembatan KA 1

Berdasarkan data pengukuran dimensi di lapangan, maka dibuat model analisa numerik dari jembatan. Berdasarkan hasil analisis numerik, maka didapatkan hasil sebagai berikut:

- Defleksi tengah bentang akibat beban RM 1921: $2.53 \mathrm{~mm}$ (beban mati) + $30.67 \mathrm{~mm}$ (beban hidup) $=33.20 \mathrm{~mm}$

- Nilai tersebut sudah melampaui syarat minimum 25 mm (L/1000; PM 60 tahun 2012), di mana $L$ adalah bentang jembatan.

\subsubsection{Jembatan KA 2}

Jembatan kedua yang dilakukan kajian terdiri dari 2 (dua) bentang jembatan plate girder beam $(8 \mathrm{~m})$ dan 3 (bentang) bentang jembatan rangka baja $(45 \mathrm{~m}, 60 \mathrm{~m}, 45 \mathrm{~m})$.

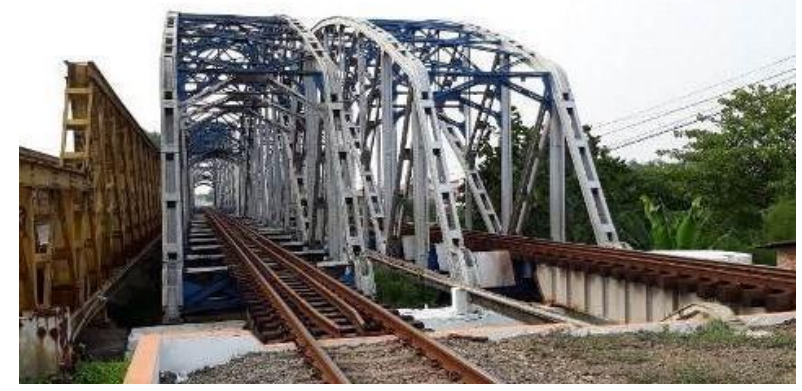

Gambar 3. Jembatan KA 2a Berupa 3 (Bentang) Bentang Jembatan Rangka Baja

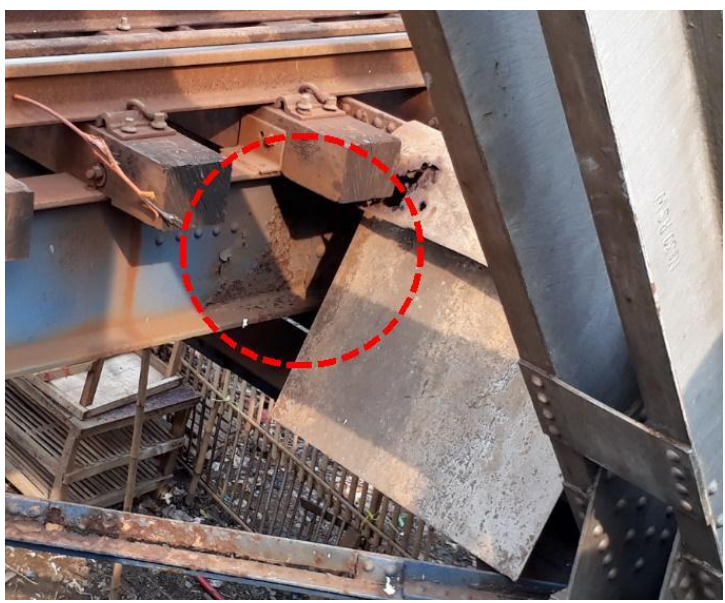

Gambar 4. Korosi pada Web dan Flange pada Plate Girder Tengah (Jembatan KA 2a)

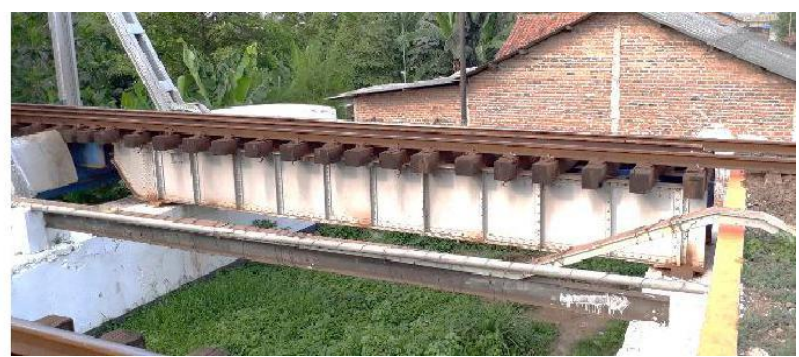

Gambar 5. Jembatan KA 2b Berupa 2 (dua) Bentang Jembatan Plate Girder Beam Bentang $8 \mathrm{~m}$

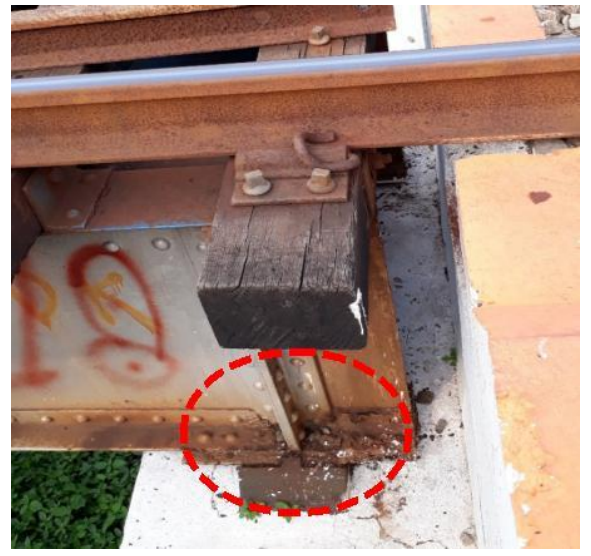

Gambar 6. Korosi pada Flange Tumpuan Jembatan Plate Girder Baja (Jembatan KA 2b)

Pada Jembatan KA 2b ini dijumpai karat yang cukup signifikan pada flange girder baja. Karat ini diperkirakan sudah mengurangi kekuatan baja, karena sudah mengurangi sebagian material pada daerah yang penting (dudukan girder).

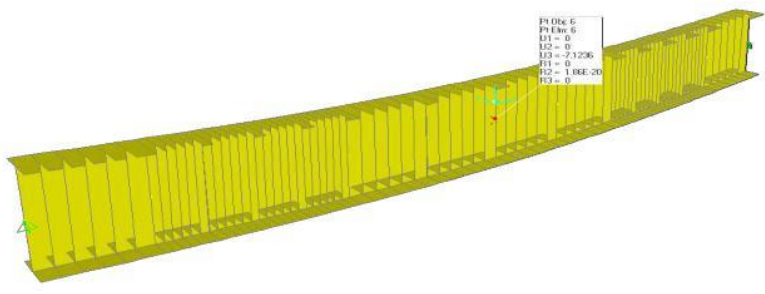

\section{Gambar 7. Model Numerik Plate Girder Beam Jembatan KA 2b}

Model numerik dibuat untuk jembatan ini, setelah dilakukan pengukuran dimensi pada jembatan eksisting. Berdasarkan hasil analisis model numerik Jembatan di atas, maka didapatkan nilai sebagai berikut:

- Defleksi tengah bentang akibat beban RM 21: $0.141 \mathrm{~mm}$ (beban mati) $+7.124 \mathrm{~mm}$ (beban hidup) $=7.265 \mathrm{~mm}$ 
- Nilai tersebut masih memenuhi syarat lendutan minimum 7.3 mm (L/1100; PM 60 tahun 2012), di mana $\mathrm{L}$ adalah bentang jembatan.

\subsubsection{Jembatan KA 3}

Jembatan ketiga yang dilakukan kajian adalah jembatan girder baja, pada sisi hilir.

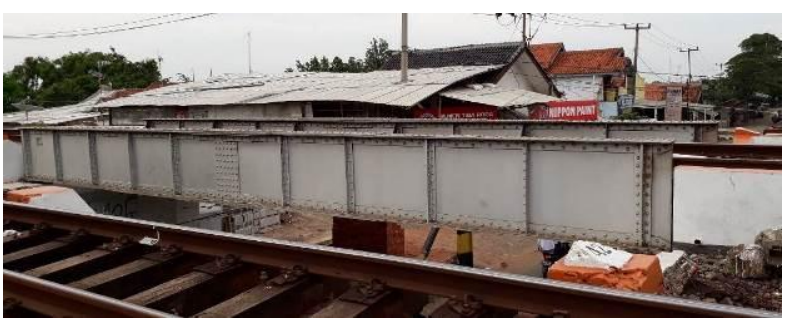

Gambar 8. Jembatan KA 3 Berupa Girder Baja Bentang 12 Meter

Model numerik dibuat untuk jembatan ini, setelah dilakukan pengukuran dimensi pada jembatan eksisting.

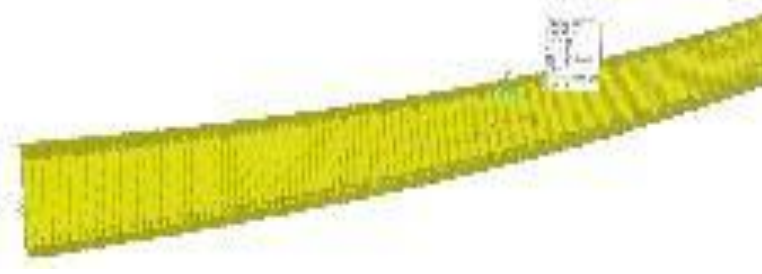

Gambar 9. Model Numerik Jembatan Girder Baja, Bentang 12 Meter

Berdasarkan hasil analisis model numerik jembatan di atas, maka didapatkan nilai sebagai berikut:

- Defleksi tengah bentang akibat beban RM 21: $0.5(\mathrm{bm})+11.2(\mathrm{bh})=11.7 \mathrm{~mm}$

- Nilai tersebut sudah melampaui syarat lendutan minimum 11.0 mm (L/1000; PM 60 tahun 2012), di mana $L$ adalah bentang jembatan.

\subsubsection{Jembatan KA 4}

Jembatan keempat yang dilakukan kajian adalah Jembatan Girder Baja, pada sisi hulu.

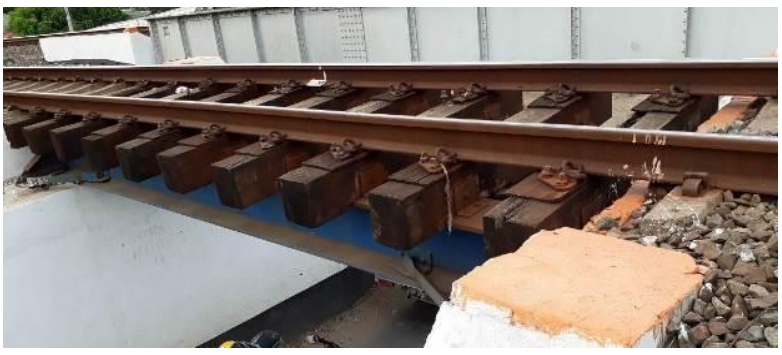

Gambar 10. Jembatan KA 4 Berupa Girder Baja, Bentang 5 Meter
Model numerik dibuat untuk jembatan ini, setelah dilakukan pengukuran dimensi pada jembatan eksisting.

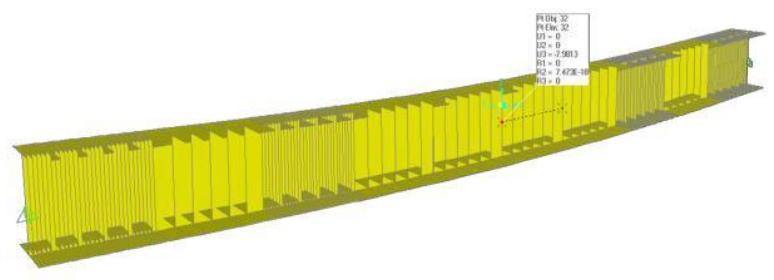

Gambar 11. Model Numerik Jembatan KA 4, Girder Baja, Bentang 5 Meter

Berdasarkan hasil analisis model numerik Jembatan di atas, maka didapatkan nilai sebagai berikut:

- Defleksi tengah bentang akibat beban RM $21: 0.13(\mathrm{bm})+7.98(\mathrm{bh})=8.01 \mathrm{~mm}$

- Nilai tersebut sudah melampaui syarat lendutan minimum $4.5 \mathrm{~mm}$ (L/1100, PM 60 tahun 2012), di mana $L$ adalah bentang jembatan.

\subsection{Pembahasan}

Berdasarkan kajian di atas, maka:

- Pada umumnya jembatan baja di lokasi kajian banyak yang mengalami karat.

- Karat-karat ini disebabkan oleh cairan limbah toilet yang tumpah dan mengenai rel maupun jembatan saat kereta melintas.

- Pencegahan terhadap karat harus dilakukan terhadap struktur-struktur baja yaitu agar cairan di atas tidak mengenai struktur baja

- Berdasarkan hasil analisis model, lendutan pada beberapa jembatan ada yang melebihi batas PM 60 Tahun 2012.

- Perlu dilakukan kaji lendutan riil jembatan akibat beban kereta api sesungguhnya dengan melakukan pengukuran defleksi jembatan

Secara garis besar, hasil-hasil di atas dibuat dalam bentuk tabel dan ditunjukkan pada Tabel 1. 
Tabel 1. Hasil-Hasil Kajian dalam Bentuk Tabel

\begin{tabular}{|c|c|c|c|c|c|c|c|}
\hline \multirow{2}{*}{ No } & \multirow{2}{*}{$\begin{array}{c}\text { Nama } \\
\text { Jembatan }\end{array}$} & \multirow{2}{*}{ Jenis } & \multirow{2}{*}{$\begin{array}{l}\text { Bentang } \\
\text { (m) }\end{array}$} & \multirow{2}{*}{ Kondisi } & \multicolumn{2}{|c|}{$\begin{array}{l}\text { Defleksi (RM21)* } \\
\qquad(\mathrm{mm})\end{array}$} & \multirow{2}{*}{$\begin{array}{c}\text { Rasio } \\
\text { tegangan } \\
\text { perlu / } \\
\text { tahanan } \\
(\mathrm{RM} 21)^{\star} \\
\text { Analisis }\end{array}$} \\
\hline & & & & & Analisis & Batas & \\
\hline 1 & Jembatan 1 & $\begin{array}{l}\text { Rangka } \\
\text { Baja }\end{array}$ & 25 & $\begin{array}{l}\text { Berkarat pada } \\
\text { flange hingga } \\
\text { tembus }\end{array}$ & 33.2 & 25.0 & 0.990 \\
\hline 2 & Jembatan $2 a$ & $\begin{array}{l}\text { Rangka } \\
\text { Baja }\end{array}$ & $45,60,45$ & $\begin{array}{l}\text { Berkarat pada } \\
\text { flange dari } \\
\text { girder tengah }\end{array}$ & & & \\
\hline 3 & Jembatan $2 b$ & $\begin{array}{l}\text { Plate } \\
\text { Girder }\end{array}$ & 8 & $\begin{array}{l}\text { Berkarat pada } \\
\text { flange dari } \\
\text { girder }\end{array}$ & 7.26 & 7.30 & 0.733 \\
\hline 4 & Jembatan 3 & $\begin{array}{l}\text { Plate } \\
\text { Girder }\end{array}$ & 12 & Baik & 11.7 & 11.0 & 0.818 \\
\hline 5 & Jembatan 4 & $\begin{array}{l}\text { Baja } \\
\text { Profil }\end{array}$ & 5 & Baik & 8.0 & 4.5 & 0.810 \\
\hline
\end{tabular}

${ }^{*}$ Catatan: Nilai di atas adalah akibat beban kereta dengan skema pembebanan RM 21; diatur dalam Peraturan Menteri Perhubungan Republik Indonesia. 2012. Persyaratan Teknis Jalur Kereta Api, Nomor PM 60 Tahun 2012

\section{KESIMPULAN}

Berdasarkan hasil kajian di atas, maka disimpulkan beberapa hal sebagai berikut:

a. Berdasarkan hasil analisis model, lendutan pada beberapa jembatan ada yang melampaui batas yang dipersyaratkan dalam PM 60 Tahun 2012.

b. Perlu dilakukan kaji lendutan riil jembatan akibat beban kereta api yang melintas dengan melakukan pengukuran defleksi jembatan pada jembatan yang hasil analisis lendutannya melampaui nilai batas.

c. Metoda di atas dapat digunakan untuk menganalisis perilaku struktur terhadap beban rencana

d. Jika hasil analisis menunjukkan perilaku yang tidak sesuai rencana dalam hal ini lendutannya, maka selanjutnya harus dilakukan pengukuran lendutan secara langsung pada jembatan akibat beban kereta.

e. Jika hasil dari pengukuran lendutan jembatan menunjukkan lendutan yang melebihi syarat, maka jembatam harus diperkaku atau bahkan diganti.

f. Pada umumnya jembatan baja di lokasi kajian banyak yang berkarat. g. Karat-karat ini disebabkan oleh cairan yang dikeluarkan oleh kereta api saat melewati rel dan jembatan.

h. Pencegahan terhadap karat harus dilakukan terhadap struktur-struktur baja yaitu agar cairan tidak mengenai struktur baja

i. Untuk mengurangi risiko bencana gagal teknologi pada jembatan kereta api, maka diperlukan pengamatan terhadap jembatan yang meliputi:

a) Pengukuran dimensi dan analisis kekuatan

b) Pengamatan visual secara berkala

c) Pengukuran lendutan jembatan akibat beban kereta secara berkala

d) Pengamatan terus menerus dengan sistem monitoring kesehatan struktur jembatan

j. Metoda-metoda yang dapat digunakan untuk memperbaiki jembatan yang diasumsikan berkurang kekuatannya adalah dengan mengganti atau menambah bagian yang rusak tersebut dengan material yang baru. Penambahan material baru harus dapat dibuktikan mampu meningkatkan kekuatan struktur.

k. Metoda-metoda pencegahan yang dapat menghindarkan berkurangnya kekuatan struktur harus diterapkan, misalnya dengan 
memberikan proteksi karat pada jembatan baja.

\section{DAFTAR PUSTAKA}

Pedoman Konstruksi Bangunan. 2009. Pemeriksaan Jembatan Rangka Baja. No. 005/BM/2009. Kementerian Pekerjaan Umum, Direktorat Jenderal Bina Marga.

Peraturan Menteri Perhubungan Republik Indonesia. 2012. Persyaratan Teknis Jalur Kereta Api, Nomor PM 60 Tahun 2012.

Presiden Republik Indonesia. 2007. UndangUndang Republik Indonesia Nomor 24 Tahun 2007, Penanggulangan Bencana. Lembaran Negara Republik Indonesia Tahun 2007 Nomor 66.

Rancangan Standar Nasional Indonesia. 2005. Perencanaan Struktur Baja untuk Jembatan, RSNI T-03-2005, Badan Standardisasi Nasional.

Standar Nasional Indonesia. 2016. Perencanaan Jembatan terhadap Beban Gempa, SNI 2833:2016, Badan Standardisasi Nasional.

Standar Nasional Indonesia. 2016. Pembebanan untuk Jembatan, SNI 1725:2016, Badan Standardisasi Nasional.

\section{UCAPAN TERIMA KASIH}

Ucapan terima kasih disampaikan kepada PT Kereta Api Indonesia, Pusat Pelayanan Teknologi BPPT, dan rekan-rekan di BPPT yang telah membantu terlaksananya kegiatan ini. 